\title{
Dr. Tetsuji Okamoto takes over as editor-in-chief
}

This issue of In Vitro Cellular and Developmental Biology-Animal is the first under the new editor-in-chief Dr. Tetsuji Okamoto. Dr. Okamoto is the Professor and Chairman of the Department of Molecular Oral Medicine and Maxillofacial Surgery in the Graduate School of Biomedical Sciences at Hiroshima University in Hiroshima, Japan. He is also the Executive Vice President of Hiroshima University. Dr. Okamoto has been a member of the Society for In Vitro Biology (formerly the Tissue Culture Association) since 1987, and he is a longstanding member and former President of the Japanese Tissue Culture Association. Dr. Okamoto received his Ph.D. in Biochemistry from the Hiroshima University School of Dentistry where he studied the effects of intermediates in cholesterol biosynthesis on the differentiation of cultured epidermal keratinocytes with Prof. K. I. Okuda. He was a postdoctoral fellow with Dr. Gordon H. Sato at the W. Alton Jones Cell Science Center in Lake Placid, NY, where he worked on growth factor purification and various aspects of cellular physiology of mammalian cells. The discovery that the most commonly used mouse myeloma cell lines in hybridoma production were cholesterol auxotrophs led to the development of a patented enhanced method of selecting hybridomas. This interest in applied basic research continues today as Dr. Okamoto studies the efficacy of lymphokine-activated killer lymphocytes in treating oral cancers and is developing serum-free culture conditions for creating and propagating human-induced pluripotent stem cells. Dr. Okamoto was elected to a professorship in the Hiroshima University School of Dentistry in 1996, and he served as the Dean of the Graduate School of Biomedical Sciences from 2007 to 2009 prior to his appointment as Executive Vice President of the university. Throughout his career, Dr. Okamoto has served In Vitro-Animal as an author, a reviewer and since 2006 as an associate editor.

It has been an honor and a privilege for me to serve as editor-in-chief of In Vitro-Animal for the past 5 years, and I thank the SIVB Board of Directors for that privilege. In that time, and especially since the 2007 inception of our association with the Springer publishing house, the number and quality of manuscripts submitted to the journal have increased. A significant proportion of submitted manuscripts and published papers now come from researchers outside the USA so there is an awareness of and a market for In Vitro-Animal beyond the USA or North American research community. I believe that the increased international exposure of In Vitro-Animal bodes well for the future of the journal. Under the leadership of Dr. Okamoto I expect the quality and reputation of the journal to continue to grow, and I hope to see a commensurate increase in the significance of In Vitro-Animal in the many research fields that make use of animal cell and tissue culture technologies.

J. Denry Sato, D.Phil

Editor-in-Chief, 2005-2010 